\title{
SAPS 3 score as a predictive factor for postoperative referral to intensive care unit
}

\author{
João M. Silva Jr. ${ }^{1,2^{*}}$, Helder Marcus Costa Rocha' ${ }^{1}$ Henrique Tadashi Katayama ${ }^{1}$, Leandro Ferreira Dias ${ }^{1}$, \\ Mateus Barros de Paula ${ }^{1}$, Leusi Magda Romano Andraus ${ }^{1}$, Jose Maria Correa Silva ${ }^{1}$ \\ and Luiz Marcelo Sá Malbouisson ${ }^{1,2}$
}

\begin{abstract}
Background: Patients undergoing intermediate-risk surgery are typically taken to the ward postoperatively. However, some may develop complications requiring intensive care later. We aimed to evaluate the characteristics of patients undergoing intermediate-risk surgery who required late postoperative admission to the intensive care unit (ICU) and determine the predictors for this.

Methods: The study included patients undergoing intermediate-risk surgery with preoperative indication for ICU but who were taken to the ward postoperatively, because they appeared to be responding well. However, they required late ICU admission. ICU care and preoperative SAPS 3 score were evaluated. Palliative surgeries and patients readmitted to ICU were excluded.

Results: The study included 100 patients, $27 \%$ of whom had late postoperative admission to the ICU. The preoperative SAPS 3 score was higher ( $45.4 \pm 7.8$ vs. $35.9 \pm 7.4, P<0.001)$ in patients who required delayed admission to the ICU postoperatively. Furthermore, they had undergone longer surgery ( $4.2 \pm 1.9$ vs. $2.7 \pm 1.5 h, P<0.001)$, and a greater proportion were gastrointestinal surgeries (14.8 vs. $5.5 \%, P=0.03$ ) and intraoperative transfusion (18.5 vs. $5.5 \% P=0.04)$. In multivariate analysis, preoperative SAPS 3 and surgery duration independently predicted postoperative ICU admission, respectively (OR 1.25; $95 \% \mathrm{Cl} 1.1-1.4$ and OR 3.33; $95 \%$ Cl 1.7-6.3).

Conclusion: The identification of high-risk surgical patients is essential for proper treatment; time of surgery and preoperative SAPS 3 seem to provide a useful indication of risk and may help better to characterize patients undergoing intermediate-risk surgery that demand ICU care.
\end{abstract}

Keywords: Surgical patients, Risk, Intensive care unit, Criteria

\section{Background}

A substantial proportion of ICU patients are surgical patients. Nevertheless, high-risk surgical patients are not often identified as such and may experience a more difficult recovery postoperatively $[1,2]$. A large observational study has indicated that surgical procedures classified as high risk have a mortality rate as high as $80 \%$ [3]. Although less than $15 \%$ of patients who underwent those procedures were admitted to an intensive care unit

\footnotetext{
*Correspondence: joao.s@globo.com

${ }^{1}$ Hospital Servidor Publico Estadual-SP, Rua Pedro de Toledo,

1800/6 A-Vila Clementino, São Paulo, SP 04039-901, Brazil

Full list of author information is available at the end of the article
}

(ICU), the individual risk is often underestimated and high-risk patient factors may be overlooked.

As in the rest of the world, the scarcity of ICU beds in Brazil is one of the most important limiting factors for admission to ICU for an eligible patient [2, 4]. Patients with a real chance of recovery are thus prioritized $[5,6]$. Surgical patients well illustrate this point, particularly those undergoing elective surgery [2]. The surgical outcome of that population is influenced not only by preoperative physiological status and surgical risk but also by adequate postoperative care [7]. Thus, it is paramount to know the predictors of the risks of increased morbidity and mortality for this group of patients [8]. 
Aiming for a better use of available resources, the Society of Critical Care Medicine has established criteria for the admission and discharge in ICUs $[5,6]$ to triage patients who may benefit most from intensive care. The proper use of such criteria is, however, not widespread, particularly in surgical patients.

Several other studies [8-11] have developed prognostic scores for critical patients and even for surgical ones $[2,7,12,13]$. However, such scores have never been used preoperatively to decide who would or would not require an ICU bed. One of those indices is the SAPS 3 prognostic system [14]. This consists of 20 easily measured parameters [15], and its results, when utilized on highrisk surgical patients, are excellent [16]. Others, such as the ASA physical status index [17], are limited in predicting worse outcomes.

The performance of prognostic models encompasses two objective measures: calibration and discrimination. Calibration refers to how closely the estimated probabilities of mortality correlate with observed mortality over the range of probabilities. Discrimination refers to how well the model discriminates between individuals who will live and those who will die. From the individual patient's point of view, a perfect discrimination would be preferable; however, for clinical trials or comparison of care between ICUs, better calibration is needed. Our intention with this study was to test the discriminatory power of preoperative SAPS 3 scores for ICU indication.

The study objective is thus to evaluate the characteristics and preoperative SAPS 3 scores of surgical patients undergoing intermediate-risk surgery, and who, owing to a decision by the surgical team, were referred to the ward postoperatively, but because of delayed postoperative complications, were admitted to ICU only later. The factors underlying such complications were also investigated.

\section{Methods}

The study was approved by the Research Ethics Committee and exempted from the signed informed consent form requirement, because it was a case-control medical record review.

The patients included in the study were those undergoing intermediate-risk surgery, defined as those for whom an ICU bed was requested at preoperative assessment for postoperative care but who were not admitted to ICU postoperatively owing to clinical evaluation at the end of the operation. Patients under the age of 18 at the time of hospitalization, patients readmitted to ICU, and those who underwent palliative surgery were excluded from the study (see Fig. 1).

Clinical evaluation performed at the end of surgery included spontaneous breathing, a tidal volume of at

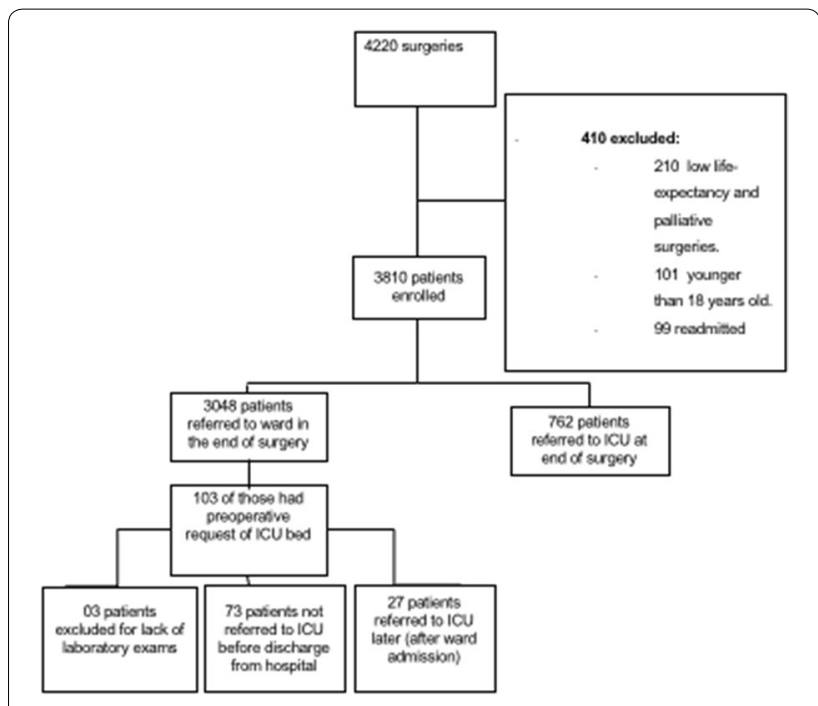

Fig. 1 Flow chart of the number of patients screened

least $6-8 \mathrm{ml} / \mathrm{kg}$ and respiratory a frequency of less than 25 breaths per minute, as well as peripheral oxygen saturation over $95 \%$ and hemodynamic stability without vasopressor support. These patients needed to be alert and fully oriented, or, in case of preoperative cognitive impairment, the level of consciousness and orientation needed to be the same preoperatively. Other criteria included lack of bleeding, satisfactory control of pain, mobilization (as far as possible), spontaneous micturition, infection parameters within normal range, and non-irritated wound conditions. Patients were evaluated based on these criteria by surgeons and anaesthesiologists who were not involved neither in the study design nor in-group allocation.

Patients who had their medical records reviewed were divided into two groups, those who had an uneventful recovery in the surgical unit and those who, owing to late postoperative complications, had to be admitted to the ICU. The reviewed data allowed the research team to calculate the preoperative SAPS 3 score $[14,18]$ and the ASA physical status [17] of patients in both groups, as well as to define their demographics, the operative procedure they underwent, operative time, whether intraoperative blood transfusion was required, and hospital mortality. To calculate the SAPS 3 score, physiological data and laboratory analysis were performed on the day before surgery. Records were reviewed from hospitalization to medical discharge or hospital mortality.

At the time of the study, there was no official directive regarding the policy of triage and reservation of ICU beds. Patients were referred to the ICU at the surgical team's discretion based on their experience. 


\section{Statistical analysis}

According to clinical experience and using the minimal clinically significant difference between groups for calculation, a sample of at least 93 participants would be required to produce a $10 \%$ chance of an alternative hypothesis (late ICU admission) and a $2 \%$ chance of a null hypothesis, accepting a type I error of 0.05 (onesided) and power of 0.95 .

Data were analysed, and the results are expressed as mean \pm standard deviation, median (interquartile range), or percentage. For statistical analysis, variables, which followed a Gaussian distribution, were evaluated for significance by using the $t$ test. Categorical variables were evaluated by the Chi-square test of contingency.

Binary logistic regression analysis was also performed, applying stepwise selection with backward elimination in order to identify independent risk factors and control confounding effects (variables mutually adjusted). Variables with significant probability ( $P$ value) of less than 0.05 in univariate analysis were considered candidates and removed in each step in the regression model if they presented a probability ( $P$ value) higher or equal to 0.10 , by likelihood ratio test. Thereafter, selected variables for the regression model were tested to evaluate pairwise interaction possibilities, and those variables with interactions were corrected in the main regression model. If no statistically significant differences were found, variables were excluded. A bootstrap procedure based on 1000 bootstrap samples was applied in the main regression model to investigate the stability of coefficients and predictive ability of the variables included in model. The $P$ values presented are from two-tailed tests, and values under 0.05 were considered statistically significant. Odds ratio and $95 \%$ confidence interval $(\mathrm{CI})$ were estimated by logistic regression. A ROC curve was determined for each variable. The cut-off points were estimated by the best sensitivity and specificity for ICU admission.

The Statistical Package for Social Sciences (SPSS-IBM Corp., Armonk, NY, USA) 21.0 was the software used for the statistical analyses.

\section{Results}

From June 2013 to December 2013, a total of 4220 patients underwent surgery at the surgical centre of the hospital. Of these patients, 413 were excluded from the study. A total of 100 records were reviewed (see Fig. 1). The mean age of the patients was 66.4 years, with a standard deviation of 14.7 years. Their average SAPS 3 score was $38.5 \pm 8.6$ and $71 \%$ were classified as ASA physical status 2. In total, $66 \%$ were women. Elective surgery accounted for $84 \%$ of cases, $30 \%$ of patients had undergone gynaecological procedures, $28 \%$ of surgeries were orthopaedic, and $16 \%$ vascular. In the cases reviewed, neuraxial block was the most used type of anaesthesia, $3 \%$ of patients died during hospitalization, and $27 \%$ had a delayed referral to the ICU (see Table 1).

When comparing both groups, SAPS 3 scores were higher among patients admitted to the ICU from the surgical unit (mean $45.4 \pm 7.8$ ) than among those who completed their recovery without ICU referral (mean $35.9 \pm 7.4, P<0.001)$. In the group of patients referred to critical care, $40.7 \%$ were considered to be in ASA physical status 3 , while only $8.2 \%$ of the patients in the other group fitted that category $(P=0.001)$. In total, $18.5 \%$ of patients in the delayed critical care group had received packed red blood cell transfusion intraoperatively, compared to only $5.5 \%$ of patients who did not need intensive care $(P=0.004)$ (see Table 2$)$.

In the multivariate analysis, the SAPS 3 score was determined as an independent factor for ICU referral (OR 1.25, $95 \% \mathrm{CI} 1.1-1.4, P=0.001$ ), as well as operative time (OR 3.33, $95 \%$ CI 1.7-6.3, $P<0.001$ ) (see Table 3).

The ROC curve area was 0.87 (95\% CI 0.78-0.93) with a 44.2 cut-off point (sensitivity: $63 \%$; specificity: $87.7 \%$ ). For operative time, the ROC curve area was 0.78 (95\% CI

\begin{tabular}{ll}
$\begin{array}{l}\text { Table } 1 \text { Demographics of the patients included in the } \\
\text { study }\end{array}$ \\
\hline Variable & Value \\
\hline Age & $66.4 \pm 14.7$ \\
SAPS 3 preoperatively & $38.5 \pm 8.6$ \\
ASA physical status P1 \% & 12.0 \\
ASA physical status P2 \% & 71.0 \\
ASA physical status P3 \% & 17.0 \\
Female gender \% & 66 \\
Elective surgery \% & 84.0 \\
Emergency surgery \% & 16.0 \\
Surgical speciality \% & \\
Gynaecology & 30.0 \\
Orthopaedics & 28.0 \\
Vascular surgery & 16.0 \\
Urological surgery & 13.0 \\
Gastrointestinal surgery & 8.0 \\
Others & 5.0 \\
Postoperative haemoglobin (mg/dL) & $12.9 \pm 1.5$ \\
ICU admission \% & 27.0 \\
PRBC transfusion \% & 9.0 \\
Hospital mortality \% & 3.0 \\
Anaesthesia \% & \\
General anaesthesia & 39.0 \\
Neuraxial anaesthesia & 49.0 \\
General plus neuraxial anaesthesia & 12.0 \\
\hline CUintensivecare unt PRBCpack & \\
\hline
\end{tabular}

ICU intensive care unit, $P R B C$ packed red blood cell transfusion; all values represent mean \pm standard deviation, Others neurosurgery, head and neck surgery, thoracic surgery 
Table 2 Comparison between patients who had uneventful recoveries in the surgical unit and patients who were referred to the ICU

\begin{tabular}{|c|c|c|c|}
\hline Variables & $\begin{array}{l}\text { ICU delayed } \\
(n=27)\end{array}$ & $\begin{array}{l}\text { Non-ICU } \\
(n=73)\end{array}$ & $P$ \\
\hline Age (years) & $65.7 \pm 16.1$ & $66.7 \pm 14.3$ & 0.75 \\
\hline Male gender (\%) & 33.3 & 34.2 & 0.93 \\
\hline Female \% (\%) & 66.7 & 65.8 & \\
\hline SAPS 3 & $45.45 \pm 7.8$ & $35.94 \pm 7.4$ & 0.000 \\
\hline ASA (\%) & & & 0.002 \\
\hline P1 & 11.1 & 12.3 & \\
\hline P2 & 48.1 & 79.5 & \\
\hline P3 & 40.7 & 8.2 & \\
\hline \multicolumn{4}{|l|}{ Surgery (\%) } \\
\hline Elective & 81.5 & 84.9 & 0.67 \\
\hline Emergence & 18.5 & 15.1 & 0.29 \\
\hline \multicolumn{4}{|l|}{ Type of surgery (\%) } \\
\hline Gynaecology & 11.1 & 37.0 & 0.02 \\
\hline Orthopaedic & 22.2 & 30.1 & 0.59 \\
\hline Vascular & 22.2 & 13.7 & 0.47 \\
\hline Urological & 18.5 & 11.0 & 0.51 \\
\hline Gastrointestinal & 14.8 & 5.5 & 0.26 \\
\hline Others & 11.1 & 2.8 & 0.24 \\
\hline Anaesthesia (\%) & & & 0.11 \\
\hline General & 55.6 & 32.9 & \\
\hline Neuroaxis & 33.3 & 54.8 & \\
\hline General + neuroaxis & 11.1 & 12.3 & \\
\hline Surgery time (h) & $4.2 \pm 1.8$ & $2.7 \pm 1.5$ & 0.000 \\
\hline $\begin{array}{l}\text { Transfusion requirements } \\
\text { intraoperatively (\%) }\end{array}$ & 18.5 & 5.5 & 0.04 \\
\hline $\begin{array}{l}\text { Value of haemoglo- } \\
\text { bin immediately } \\
\text { postoperatively(mg/dL) }\end{array}$ & $12.5 \pm 1.6$ & $12.9 \pm 1.5$ & 0.20 \\
\hline Hospital mortality (\%) & 11.1 & 0.0 & 0.004 \\
\hline $\begin{array}{l}\text { Length of hospital stay } \\
\text { (days) }\end{array}$ & $23.0 \pm 22.2$ & $25.8 \pm 31.7$ & 0.410 \\
\hline
\end{tabular}

ICU intensive care unit, Others neurosurgery, head and neck surgery, thoracic surgery; all values represent mean \pm standard deviation
0.689-0.859), with a 3-h cut-off point (sensitivity: $74.1 \%$; specificity: $83.6 \%$ (see Fig. 2).

Patients with a preoperative SAPS 3 score exceeding 40 had a higher rate of ICU referral (see Fig. 3).

\section{Discussion}

The identification of intermediary-risk surgical patients likely to require ICU care is difficult. To optimize postsurgical care and to prevent under and overuse of ICUs, criteria must be developed. We found that SAPS 3 scores and operative time were significantly higher in patients who eventually require critical care, showing that they could be used to predict early postoperative ICU necessity.

Predicting postoperative ICU need is complex in surgical patients. There are no self-evident criteria because many patient- and procedure-related factors determine ICU need. Because of the lack of objective criteria, many unnecessary admissions occur [11]. In this study, special attention was given to identifying which criteria could be used in practice to triage surgical patients and to determine which population found itself at higher surgical risk.

In multivariate analysis, predictive factors for delayed postoperative ICU admission were SAPS 3 score (OR 1.25 IC $95 \% 1.1-1.4$ ) and operative time (3.33 IC $95 \%$ 1.7-6.3). In a recent study, Silva et al. [16] demonstrated the applicability of SAPS-3 in Brazilian hospitals, supporting its validation for surgical patients, consistent with other studies [13]. SAPS 3 is distinct from other prognostic scores because it is simple and does not require the use of sophisticated technological resources or complex data. Operative time is also easily obtained from the anaesthesia record.

Further studies have reached the same conclusion: postoperative risk is easily underestimated in clinical evaluation immediately postoperatively [3, 19]. In our study, $27 \%$ of patients for whom an ICU bed had been

Table 3 Logistic regression for delayed ICU

\begin{tabular}{|c|c|c|c|c|c|c|}
\hline & \multirow[t]{2}{*}{$P$} & \multirow[t]{2}{*}{ OR } & \multicolumn{2}{|c|}{$95 \% \mathrm{Cl}$} & \multicolumn{2}{|c|}{ Bootstrap $95 \% \mathrm{Cl}$} \\
\hline & & & Lower & Upper & Lower & Upper \\
\hline SAPS 3 (per unit) & 0.001 & 1.253 & 1.102 & 1.425 & 1.24 & 1.893 \\
\hline Surgery time (per hour) & 0.000 & 3.327 & 1.750 & 6.325 & 2.235 & 8.618 \\
\hline ASA physical status (per unit) & 0.991 & 0.991 & 0.207 & 4.749 & -1.926 & 6.703 \\
\hline Transfusion requirements & 0.593 & 1.737 & 0.230 & 13.145 & -1.128 & 18.526 \\
\hline Gynaecological surgery & 0.270 & 0.199 & 0.011 & 3.491 & -19.662 & 4.161 \\
\hline
\end{tabular}

The variables were adjusted in model by ASA, transfusion and surgery. Unless otherwise stated, the bootstrap results are based on 1000 bootstrap samples 


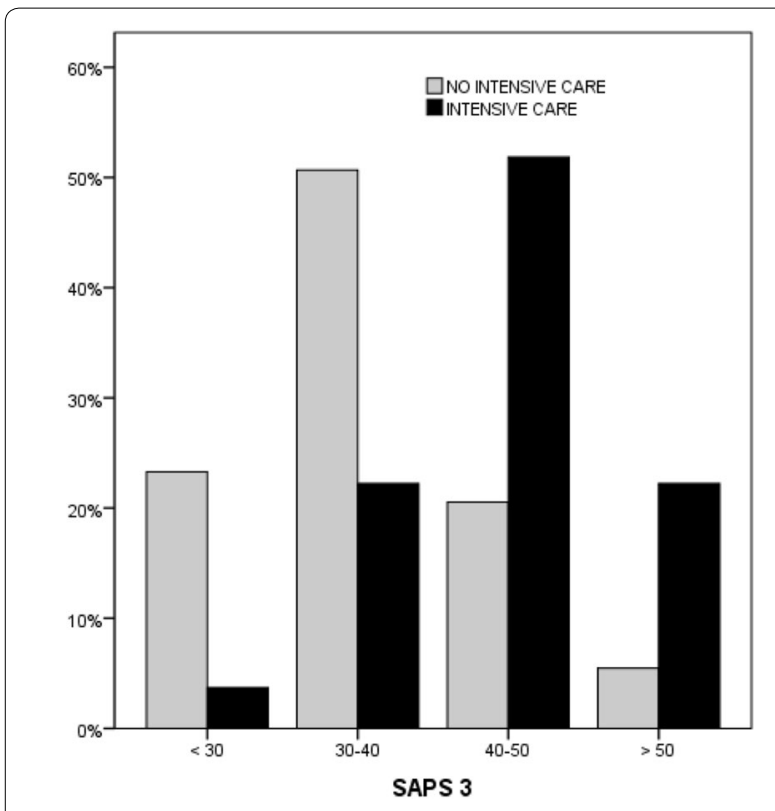

Fig. 2 ROC curves of surgery time and SAPS 3 score for ICU referral

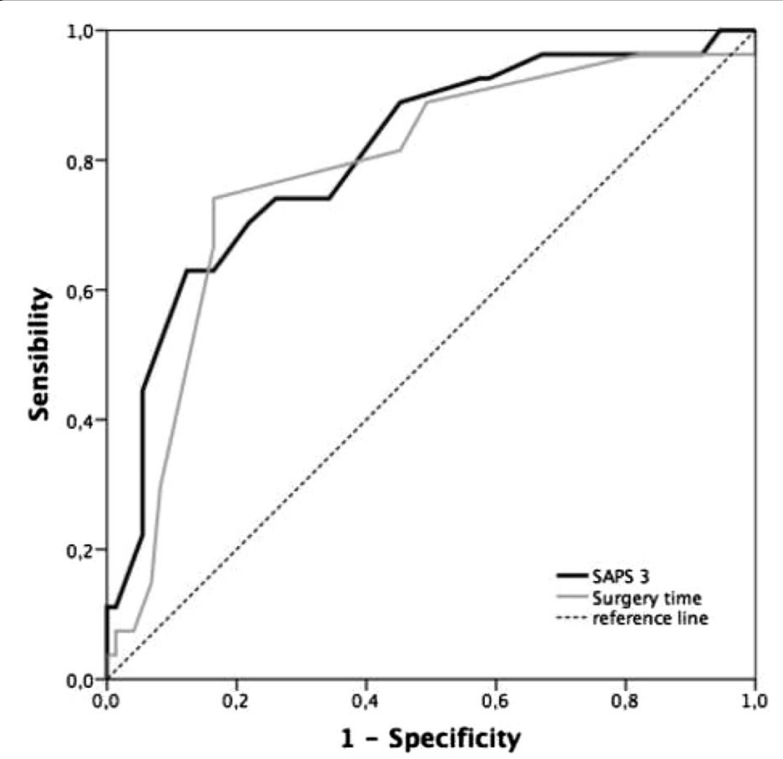

Fig. 3 SAPS 3 score stratification and ICU referral rate

requested but who were not taken to the ICU because they were evaluated as well enough to be cared for in the surgical unit, eventually had to be admitted to the ICU. Their postoperative complications might have been avoided if the request for an ICU bed had been met. This high incidence of late admission to the ICU illustrates the low predictive quality of the criteria used by the surgical team when deciding where the patient should be during the postoperative period, although the rate of refused ICU admissions for surgical patients is lower than that for non-surgical ones [20,21].

For non-surgical patients, the age, severity of illness, and medical diagnosis are independent factors for ICU admission [22]. For surgical patients, it has been demonstrated that peritonitis, unplanned surgery, age, elevated serum lactate level, and a high central venous pressure on the day of ICU admission were independent predictors of death as a result of multiple organ failure [23]. Most of those factors are measured postoperatively. Identifying early predictors of postoperative complications might assist in the development and implementation of preventive measures.

The importance of preoperative planning is evident in the higher mortality rate of patients with late ICU admission. A late diagnosis and, therefore, a late referral to the ICU severely increase the chance of permanent damage to vital functions [23].

Clinical postoperative evaluation is too imprecise to identify surgical patients with a high risk of complications and may cause costly delays in adequate treatment. For $11 \%$ of late admission patients in our study, this delay proved fatal.

Such complications result in longer hospitalizations, attended by problems such as sepsis, delirium, and organ failure [24]. Therefore, a clear set of objective criteria for ICU admission is important [6].

Findings indicate that subjective, individual analysis of a patient's prognosis as well as isolated clinical parameters may lead to underestimation of the risk of complications and a delay in ICU referral [25].

Nowadays, there are few ICU admission guidelines [2, $4]$, and they are not widely utilized in clinical practice, particularly in the case of surgical patients.

The prediction of the SAPS 3 model is based exclusively on data evaluated within the first hour, which does not the case with other scores. Besides, the predictive power of the original SAPS 3 score is derived from information evaluated before ICU admission. Prognostic systems that include measurement up the first $24 \mathrm{~h}$ of ICU period are unavailable for use in the ICU screening. Furthermore, values above $24 \mathrm{~h}$ often capture the standard of care more than the actual clinical state of the patient; in this case, for example, the SOFA or APACHE scores may fall. This is the greatest advantage of SAPS 3, confirming its superiority over other prognostic scores in screening ICU patients. Other scoring systems, such as ASA-PS, do not include variables specific to the surgical procedure and are disadvantageous in their subjectivity.

The current study has some limitations. It is an observational study, which makes renders the potential for error high, even though enough statistical power was 
achieved. Another limitation is that it was conducted at a single surgical centre and that the sample size is small. Likewise, five variables were included in a logistic regression which evaluates only 27 events, but a bootstrap procedure was made based on 1000 bootstrap samples in order to investigate the stability of coefficients and predictive ability of the variables included in model, and a small amount of variation was found while the number of samples had increased considerably. Additionally, variables might have been overlooked and should constitute the subject of further analysis. For example, all patients requiring ICU care preoperatively could be included; in this way, patients who eventually went to ICU as predicted, those who did not go to ICU but were later admitted and those who never had to go to ICU, might be compared. Although the model applicable to all types of surgery, we have no data on its usefulness and predictability in other groups of patients. Further studies in different patient groups with different models are needed to determine the best predictive model.

\section{Conclusion}

Preoperative SAPS 3 scores and surgery time are valuable tools for predicting the severity of illness and the risk of postoperative complications that might require intensive care. They were the most relevant factors analysed in this study.

More studies are required on this subject. The costeffectiveness of precise indications of postoperative intensive care justifies further research.

\section{Authors' contributions \\ JMSJ is the guarantor of the integrity of the data and the accuracy of the data analysis. JMSJ, HMCR, and HTK designed the study. LMSM performed the statistical analysis. JMSJ, HMCR, HTK, LFD, MBP, LMRA, JMCS, and LMSM contributed substantially to the collection of data, data analysis, and interpre- tation and to the writing of the manuscript. All authors read and approved the final manuscript.}

\section{Author details \\ 1 Hospital Servidor Publico Estadual-SP, Rua Pedro de Toledo, 1800/6 A-Vila Clementino, São Paulo, SP 04039-901, Brazil. ${ }^{2}$ Anaesthesiology Department, Hospital das Clinicas SP-FMUSP, Av. Dr. Enéas de Carvalho Aguiar, 255 Cer- queira César, São Paulo, SP 05403-000, Brazil.}

\section{Competing interests}

The authors declare that they have no competing interests.

Received: 13 July 2015 Accepted: 21 March 2016

Published online: 30 April 2016

\section{References}

1. Silva JM Jr, Oliveira AM, Segura JL, Ribeiro MH, Sposito CN, Toledo DO, Rezende E, Malbouisson LM. A large venous-arterial PCO(2) is associated with poor outcomes in surgical patients. Anesthesiol Res Pract. 2011;2011:759792.

2. Caldeira VM, Silva Junior JM, Oliveira AM, Rezende S, Araujo LA, Santana MR, Amendola CP, Rezende E. Criteria for patient admission to an intensive care unit and related mortality rates. Rev Assoc Med Bras. 2010;56(5):528-34.

3. Jhanji S, Thomas B, Ely A, Watson D, Hinds CJ, Pearse RM. Mortality and utilisation of critical care resources amongst high-risk surgical patients in a large NHS trust. Anaesthesia. 2008;63(7):695-700.

4. Simchen E, Sprung CL, Galai N, Zitser-Gurevich Y, Bar-Lavi Y, Gurman G, Klein M, Lev A, Levi L, Zveibil F, et al. Survival of critically ill patients hospitalized in and out of intensive care units under paucity of intensive care unit beds. Crit Care Med. 2004;32(8):1654-61.

5. Anonymous. Guidelines for developing admission and discharge policies for the pediatric intensive care unit. Pediatric Section Task Force on Admission and Discharge Criteria, Society of Critical Care Medicine in conjunction with the American College of Critical Care Medicine and the Committee on Hospital Care of the American Academy of Pediatrics. Crit Care Med. 1999;27(4):843-5.

6. Anonymous. Guidelines for intensive care unit admission, discharge, and triage. Task Force of the American College of Critical Care Medicine, Society of Critical Care Medicine. Crit Care Med. 1999;27(3):633-8.

7. Bennett-Guerrero E, Hyam JA, Shaefi S, Prytherch DR, Sutton GL, Weaver PC, Mythen MG, Grocott MP, Parides MK. Comparison of P-POSSUM riskadjusted mortality rates after surgery between patients in the USA and the UK. Br J Surg. 2003:90(12):1593-8.

8. Marshall JC, Cook DJ, Christou NV, Bernard GR, Sprung CL, Sibbald WJ. Multiple organ dysfunction score: a reliable descriptor of a complex clinical outcome. Crit Care Med. 1995;23(10):1638-52.

9. Le Gall JR, Klar J, Lemeshow S, Saulnier F, Alberti C, Artigas A, Teres D. The Logistic Organ Dysfunction system. A new way to assess organ dysfunction in the intensive care unit. ICU Scoring Group. JAMA. 1996;276(10):802-10.

10. Knaus WA, Draper EA, Wagner DP, Zimmerman JE. APACHE II: a severity of disease classification system. Crit Care Med. 1985;13(10):818-29.

11. Kose I, Zincircioglu C, Cakmak M, Cabbaroglu G, Senoglu N, Gonullu M. Postoperative patients in the intensive care unit: Identifying those who do not really need it. J Crit Care. 2015;30(6):1295-8.

12. Sakr Y, Krauss C, Amaral AC, Rea-Neto A, Specht M, Reinhart K, Marx G. Comparison of the performance of SAPS II, SAPS 3, APACHE II, and their customized prognostic models in a surgical intensive care unit. $\mathrm{Br} J$ Anaesth. 2008;101(6):798-803.

13. Nassar APJ, Malbouisson LM, Moreno R. Evaluation of simplified acute physiology score 3 performance: a systematic review of external validation studies. Crit Care. 2014;18(3):R117.

14. Moreno RP, Metnitz PG, Almeida E, Jordan B, Bauer P, Campos RA, lapichino G, Edbrooke D, Capuzzo M, Le Gall JR. SAPS 3-From evaluation of the patient to evaluation of the intensive care unit. Part 2: Development of a prognostic model for hospital mortality at ICU admission. Intensive Care Med. 2005;31(10):1345-55.

15. Soares M, Salluh J. Validation of the SAPS 3 admission prognostic model in patients with cancer in need of intensive care. Intensive Care Med. 2006;32(11):1839-44.

16. Silva Junior JM, Malbouisson LM, Nuevo HL, Barbosa LG, Marubayashi LY, Teixeira IC, Nassar Junior AP, Carmona MJ, Silva IF, Auler Junior JO, et al. Applicability of the simplified acute physiology score (SAPS 3) in Brazilian hospitals. Rev Bras Anestesiol. 2010;60(1):20-31.

17. Keats AS. The ASA classification of physical status - a recapitulation. Anesthesiology. 1978:49(4):233-6.

18. Metnitz PG, Moreno RP, Almeida E, Jordan B, Bauer P, Campos RA, lapichino G, Edbrooke D, Capuzzo M, Le Gall JR. SAPS 3-From evaluation of the patient to evaluation of the intensive care unit. Part 1: Objectives, methods and cohort description. Intensive Care Med. 2005;31(10):1336-44.

19. Lobo SM, Rezende E, Knibel MF, Silva NBd, Páramo JAM, Nácul F, Mendes CL, Assunção M, Costa Filho RC, Grion CC, et al. Epidemiology and outcomes of non-cardiac surgical patients in Brazilian intensive care units. Rev Bras Ter Intensiva. 2008;20(4):376-84.

20. Sprung CL, Danis M, Baily MA, Chalfin DB, Dagi TF, Davila F, De Vita M, Engelhardt TH Jr, Grenvik A, Hofmann PB, Hoyt JW, Kofke WA, Lynn J, Marshall MF, McCartney JJ, Nelson RM, Ninos N, Raphaely RC, Reardon F, Rie MA, Rosenbaum SH, Silverman H, Sottile FD, Spanier A, Steinberg A, Tendier RMD, Teres D, Truog RD, Wallace TE, Wlody G, Yeh TS. Consensus statement on the triage of critically ill patients. Society of Critical Care Medicine Ethics Committee. JAMA 1994;271(15):1200-3. 
21. Marshall MF, Schwenzer KJ, Orsina M, Fletcher JC, Durbin CG Jr. Influence of political power, medical provincialism, and economic incentives on the rationing of surgical intensive care unit beds. Crit Care Med. 1992;20(3):387-94.

22. SinuffT, Kahnamoui K, Cook DJ, Luce JM, Levy MM, Values E. Rationing in critical care task F: rationing critical care beds: a systematic review. Crit Care Med. 2004;32(7):1588-97.

23. Lobo SM, Rezende E, Knibel MF, Silva NB, Paramo JA, Nacul FE, Mendes $\mathrm{CL}$, Assuncao M, Costa RC, Grion CC, et al. Early determinants of death due to multiple organ failure after noncardiac surgery in high-risk patients. Anesth Analg. 2011;112(4):877-83.
24. Higgins TL, McGee WT, Steingrub JS, Rapoport J, Lemeshow S, Teres D. Early indicators of prolonged intensive care unit stay: impact of illness severity, physician staffing, and pre-intensive care unit length of stay. Crit Care Med. 2003;31(1):45-51.

25. Wilkinson D. The self-fulfilling prophecy in intensive care. Theor Med Bioeth. 2009;30(6):401-10.

\section{Submit your manuscript to a SpringerOpen ${ }^{\circ}$ journal and benefit from:}

- Convenient online submission

\section{- Rigorous peer review}

- Immediate publication on acceptance

- Open access: articles freely available online

- High visibility within the field

- Retaining the copyright to your article 